\title{
1. Introduction to Policy Change and Innovation in Multilevel Governance
}

\section{GOVERNANCE IN TURBULENT TIMES}

People prefer stability, and governments are expected to provide for stable conditions. However, we live in turbulent times, and turbulence has become a topic of academic literature on governance (Ansell and Bartenberger 2017). Since the turn of the century, liberal capitalism has gone through a deep crisis with its global financial markets; societies all over the world are affected by the digital revolution; climate change has become a reality which nobody recognizing empirical evidence can neglect; and new and old kinds of wars, dictatorships and governance failure in countries at the fringes of modern democratic states have caused rising immigration into affluent societies, the consequence of which bring new social cleavages in additions to those caused by an aging population. Further, in January 2020 the outbreak of the COVID-19 pandemic shocked people all over the world. As to the political order, emergent patterns of international governance are in flux, European integration is threatened by internal divides and disintegrative processes, nation states are confronted by demands for regional autonomy, and established representative democracies are exposed to changes in party systems, populism, polarization and citizens' rising discontent.

These crises and transformative processes had and still have far-reaching impacts on government and public administration. Coping with climate change, governing the internet, regulating global capitalism, restructuring the welfare state, controlling migration, resolving violent conflicts, fighting terrorism, containing the spread of pathogenic germs, holding together constituent units of multinational polities and solving political conflicts in fragmented and polarized party systems are demanding tasks. They raise 'wicked problems', which are complex, intractable, undefined, unique, persistent and unpredictable regarding their evolution and consequences (Alford and Head 2017; Danken et al. 2016). Neither experts nor parties can claim to know how to solve these problems, and even if responsible actors come to an agreement or a decision on a possible solution, no single authority is capable of its implementation without the support or acceptance of public or private actors. Yet 
in a turbulent context, existing policies certainly must be adjusted to changing conditions, innovative policies need to be elaborated, and these policies have to be implemented in structures and processes reflecting the complexity of existing and imminent problems. Evidently, dealing with the challenges mentioned above requires new approaches of public policymaking in a number of fields such as welfare, public health, education, the economy, the environment, energy and fiscal policy.

Significant policy changes first and foremost concern goals, programmes, rules or instruments. However, in order to make and implement them, institutions and procedures need to be modified accordingly. Over the last decades, many governments have engaged in processes of institutional reform addressing the division of responsibilities and procedures of coordination or administrative organization. Since most of the challenges mentioned above cut across borders of existing jurisdictions, various patterns of multilevel governance emerged along with a reallocation of powers between local, regional and national governments, often in consequence of a delegation of powers to European authorities or to international organizations, administrations or regimes (Hooghe et al. 2016a, 2016b; Hooghe et al. 2010; Hooghe et al. 2019). Moreover, liberalization and deregulation of markets have led to the privatization of public utilities and services and have modified the public-private divide, with the consequence that policies addressing social costs and market failure require new institutional frameworks (Leibfried and Zürn 2005). In many states, in the EU and in international organizations, constitutions or statutes have been amended accordingly, in line with procedures and according to decision rules, which actually had been designed to protect the status quo. Public administration has gone through a series of reforms and adjustments, which started with New Public Management, followed by joined-up government or other attempts to improve coherence or coordination (Pollitt and Bouckaert 2017). Structures, responsibilities and policymaking have been adjusted to the Europeanization of administration, the rise of international public administration, the foundation of independent agencies, and changes in multilevel, interjurisdictional or public-private cooperation. In order to implement the required policy changes, new modes of coordination and control in the increasingly complex structures seem to be essential. In any case, continuing debates on the performance of public administration and the outcomes of reforms demonstrate that ambitious aims and the envisaged designs have rarely been achieved so far, and that there is still pressure for institutional change.

All these challenges and turbulences have been felt in most parts of the world, but they particularly affect highly developed Western democracies that have been embedded in international economy and politics for a long time. Governments of these states either are responsible for the global problems, 
are affected by them or control the means or resources required to manage the problems. In order to cope with the major problems, they have to elaborate and implement appropriate policies which significantly depart from those that are in place. However, if finding the right response to problems is a demanding task on its own, procedures of democracy and the division of power make policy change rather difficult. And things become more toilsome since governments cannot solve problems on their own but have to manage interdependence among states and among different scales of multilevel political systems.

For this reason, whenever political scientists analyse and evaluate the performance of governance and public policies in contemporary democratic governments and the challenges of these fundamental societal or pressing global problems, they point out a gap between the need for change and the capacities for change. This kind of reasoning resonates with debates in the 1970s, when scholars diagnosed a crisis of governability. They assumed that rising demands from powerful pressure groups or citizens exceeded the capacities or resources of governments (Crozier et al. 1975) and that parliaments or governments lack the expertise necessary to regulate complex technologies. Some scholars revitalized neo-Marxist crisis theories to explain an inevitable failure of governance (Jessop 2002). Nowadays, scholars applying a society-centred approach no longer identify power relations between classes but the uncontrollable mobility of private corporations, goods and capital across jurisdictions of governments as the main causes of existing problems (Streeck 2014). The debate focuses on the incongruence between spaces of democratic politics and spaces of policymaking (Papadopoulos 2010), with the latter following functions, whereas democratic government is organized on a territorial basis. In consequence, policymaking is characterized by a plurality of actors, complex interactions and variable governance arrangements cutting across boundaries of institutions and borders of jurisdictions. With the growing interlocking of local, regional, national, European and international processes of politics, each of which mobilizes different types of actors (elected and non-elected, public and private, generalists and specialists; Piattoni 2018), the diversity of issues and interests to be taken into account, and the number of veto players to be included in decision making, has increased tremendously. This high complexity of governance makes political decisions in general - and policy change in particular - difficult.

Accordingly, governments in Western democracies seem to have run into a dilemma: On the one hand, a division of powers, accountability of policymakers and multilevel governance constitute essential conditions for governing contemporary societies. They prevent governments from ignoring the fundamental rights of citizens or the relevant interests of social groups, they provide for legitimacy and acceptance of decisions and they allow for the consideration of different impacts of policies on various stakeholders in 
society and territories at different scales. On the other hand, institutional constraints due to divided responsibilities or countervailing powers, complicated processes of coordination between actors affiliated to different organizations or jurisdictions, and imminent opposition of veto players constitute obstacles to achieving meaningful policy change or innovation. Incremental evolution is said to be the rule, with significant change to occur only under exceptional, contingent circumstances (categorized as 'critical junctures', 'windows of opportunities', 'focusing events', see Chapter 3). However, given the current challenges governments have to cope with, neither gradual adjustment of policies nor the fatalist waiting for promising opportunities for change seem appropriate.

Scholars working on public administration and management have suggested interorganizational and interjurisdictional collaboration, the inclusion of stakeholders and network management as viable strategies to cope with prevailing problems (Ansell and Gash 2008; Fischer 2018; Lazega 2020; Provan and Kenis 2008; Sørensen and Torfing 2017). In contrast, scholars working on multilevel governance have raised doubts that policy innovation is feasible by these processes (Scharpf 1988). Revealing the transformation of nation states, multilevel governance has been driven by actor mobilization in the regional or international realm and the shift of power or migration of authority (Hooghe and Marks 2001). However, while dynamics of governance structures might express significant change, it is not known whether this change contributes to effectiveness of governance and policymaking. Depending on the decision rules in multilevel policymaking, policy change is defined by a powerful agenda setter, by a majority of actors in a decision making body or by the lowest common denominator resulting from negotiations. Actors who are involved in these processes need to coordinate policies, but need also to take into account rules and politics within their 'home institution' or the specific interest of the organization or government they represent. Although emerging informal policy networks cutting across organizational boundaries or jurisdictions may favour deliberation on the knowledge, opinions and preferences of the different actors and can induce policy learning, the impact of 'network governance' on final decisions according to formal procedures within governments or organizations is all but certain. For these reasons, significant change seems to be unlikely.

This dilemma of multilevel governance and the state of research appear to invite diverging normative conclusions. In general, scholars take the transformation of government into highly complex structures which include a plurality of actors as a necessary condition for managing entangled problems, but they also highlight the deficit of democratic legitimacy and search for new configurations of democracy. In the wider public, populist reasoning seems to attract increasing attention - not least in response to the debate on 
the democratic deficit. It evokes calls for strong leadership, radical institutional reforms reducing power-sharing, or for curtailing the participation of organized interests, which should be replaced by the direct decisions of the people. Others are fascinated by technocratic government, with China serving as a model. Daniele Caramani clearly demonstrated that multilevel 'modes of governance provide a fertile soil for populist critique. Citizens are presented as feeling distant from processes that are complex, non-transparent and lacking democratic legitimacy, all of which justifies malaise and antiestablishment discourses' (Caramani 2017: 58). And he continues: 'From a technocratic view, however, complexity calls not simply for more popular participation but also for less and for entrusting its management to experts' (ibid.).

These suggestions are problematic from a normative and a practical point of view. They question or neglect basic principles of democratic legitimacy, although they highlight the will of the people or presume to aim at the common good. In particular, these claims appear as unrealistic, and neither the populist nor the technocratic ideal of governance can work in practice. Political leaders might have the power to change policies, but there is no guarantee that they are able to solve entangled problems, not least as populists prefer a return to the nation state. Technocrats might have expertise, but beyond that a plurality of interests have to be taken into account. Therefore, experts might propose innovative policies, but a technocratic approach cannot solve conflicts which are likely to arise.

Still no less problematic is the state of theorizing on policymaking in multilevel governance which points in different directions. Certainly, theories cannot provide substantial solutions for the wicked problems mentioned at the outset. However, since these challenges have to be addressed by governments and call for significant policy change and innovative policies, the ambivalence of research results and theoretical reasoning concerning the capacity of governments to change policies seems unsatisfactory. As long as we cannot demonstrate that significant policy change is possible in complex structures of multilevel governance, we cannot prevent public debates from falling into the traps of populism and technocratic functionalism.

These looming consequences have motivated me to write this book. Focusing not only on policy change but also on the more demanding version of policy innovation, it neither neglects the various constraints limiting governance in multilevel structures nor does it overestimate the chances of policy or institutional reforms. Far from assuming that policy innovation is the rule or can be achieved without major difficulties, I nonetheless claim that it is not impossible. The basic argument to be elaborated in the following chapters holds that complexity in multilevel systems does not rule out policy innovation. These systems establish both favourable and constraining conditions for significant change. Whether policy ends with innovative decisions, 
gradual change or deadlock depends on the particular patterns of multilevel governance and additional conditions. In order to show that policy innovation occurs not only coincidentally but in specific patterns of governance and under conditions that can be shaped by policymakers, we need to identify these patterns and conditions. This is the aim of this book, which thus makes the claim against calls for a concentration of power in the hands of populist leaders or technocrats.

\section{THE CONCEPT OF MULTILEVEL GOVERNANCE}

This book is about policy change and innovation in multilevel governance. It does not explain how policy innovation can be achieved in general. The following chapters should contribute to research on policymaking under the conditions of multilevel governance, assuming that the structures and processes cutting across jurisdictions of governments or political organizations beyond the nation state do not rule out changing a policy, although they imply considerable obstacles for policy innovation. This specific focus is justified by the need for innovative policies in view of the wicked problems mentioned above and the fact that multilevel governance has become the 'conditio politica of the twenty-first century' (Zürn 2010: 82).

The concept of multilevel governance emerged in different contexts of political science and has been applied in studies on comparative federalism, European integration, international relations and public administration (Bache and Flinders 2015; Benz et al. 2021; Enderlein et al. 2010; Ongaro et al. 2010). Some use the concept to label a theoretical approach, others to describe a structure of territorial politics, and yet others to characterize a pattern of governing. Over time it has lost its contours, when it 'has been thrown around by scholars like a favourite coat - a staple item in the European political science wardrobe, but perhaps one worn so often that it has now become threadbare', as Paul Stephenson (2013: 818) put it in a review of the state of research. Governance or multilevel governance has often been characterized as a network-like pattern of interaction among actors representing local, regional or national governments, the European Union or international organizations including private actors like firms, associations or NGOs. The inclusion of private actors has been said to distinguish multilevel governance from the traditional concept of 'intergovernmental relations' among executives and should imply a broader perspective on actors and structures (Alcantara et al. 2016). Accordingly, Ian Bache and Mathew Flinders highlighted two facets of the multilevel governance concept: "Multi-level" referred to the increasing interdependence of governments operating at different territorial levels, while "governance" signalled the growing interdependence between governments and non-governmental actors at various territorial levels' (Bache 
and Flinders 2004: 3). Yet the participation of stakeholders or private actors is not a distinguishing feature nor is it sufficient to understand the complexity of multilevel governance, which the concept of intergovernmental relations does not apprehend either.

In fact, a two-dimensional conceptualization appears essential (Benz 2009), one that focuses on governments but does not preclude that private actors participate in policymaking. If we consider multilevel governance in the world of democratic governments, policies are actually coordinated by executives or party leaders who interact across levels in 'boundary-spanning' roles, but remain responsible within their government, usually being accountable to parliaments and the parties supporting them. Hence the intergovernmental arena is linked to the arena of democratic politics, where the preferences of actors involved in multilevel policymaking are formulated or at least have to be accepted by assemblies of elected representatives or members holding executives to account. Like in 'intergovernmental' relations, interest groups or stakeholders may partake in these 'intragovernmental' processes, but this is not a defining feature of democratic governance, although it modifies the type of democracy. For comprehending multilevel governance, it is essential to take into account the interplay between the intra- and intergovernmental arenas; that is, the different sites of policymaking defined by specific functions, actor constellations and rules of interaction. Arenas emerge in the context of institutions but are defined by real interactions which are not necessarily congruent with institutions. Due to the different functions, mechanisms of decision making and power structures, the processes within these arenas, which are connected in multilevel governance, can produce conflicting effects which complicate policymaking and make change and innovation difficult.

\section{POLICY CHANGE AND POLICY INNOVATION}

Like multilevel governance, policy change is a widely used concept in social science without scholars having agreed on a common understanding (Hall 1993; Howlett and Cashore 2009; Jenkins-Smith and Sabatier 1993; Knill et al. 2010). Based on this literature, policy change can be defined as an amendment or replacement of existing rules or programmes that are designed to influence the behaviour of actors in state or society, including the resources of these actors. Moreover, effective change implies either a certain compliance of actors addressed by a policy or the execution of amended or new rules or programmes by responsible administrations. Compliance or implementation determine the outcome of a policy, revealed by the actual changes in behaviour of those addressed by the programme. These effects of a policy change might conform to the intentions of policymakers and solve problems at stake, or they may not fulfil the expectation. As a rule, we should expect some kind of 
impact of political decisions. Change covers any deviation from the status quo of rules, programmes and their effects (outcomes or impacts), with the relevant substance of change (what changes) being defined by the agenda of a policy.

For political scientists, the concept of policy change raises three questions: What changes, to what extent does change materialize, and how effective is change? The first question concerns the substance of a policy and relates to the social field and the problems addressed. Following (Lowi 1972), policy scientists distinguish regulative, distributive, redistributive and constitutional policies. Accordingly, change can find expression in new or revised legal rules or emergent social norms, the allocation of resources, goods or services to specific types of actors (such as families with dependent children, students, the unemployed), a modification of the existing allocation of resources among groups, organizations or actors with some benefiting and others losing, or an amendment of those rules or norms that establish or define a group or organization, including basic rules of operation. Other things being equal, redistributive and constitutional policies instigate more intense conflicts and resistance than regulative or distributive policies. Furthermore, significant policy change inevitably comes with redistributive effects, and constitutional amendments can involve value and identity conflicts.

The second question points to the relation between the status quo, an agenda and the outcome of policymaking. Compared to the status quo, we can distinguish incremental, significant and transformative change. Regarding an agenda, policies can alter the means or instruments applied to influence the behaviour of actors addressed. This 'first order change' can be exemplified by the increase, decrease, abolition or replacement of subsidies, services or taxes. Moreover, the agenda can set new aims or more ambitious targets, like, for instance, the reduction of greenhouse gases. Finally, change can be expressed in a new policy paradigm (Hall 1993) and lead a transformation of a 'policy regime' including power structures and institutions.

The third aspect draws attention to the distinct processes of the policy cycle, in particular the formulation of rules or programmes, their implementation, and the compliance or noncompliance of actors addressed. Policy change can materialize in output, outcome and impact, but it can also be limited to either output and outcome or only output. Accordingly, we can distinguish effective, ineffective and failed policy change. In the first case, decisions by policymakers are implemented, and those addressed by a policy comply and adjust their behaviour with the consequence that a changed policy achieves its intended impact on a policy field or a social field. Policy change is ineffective if a decision is implemented and the actors addressed adjust their behaviour but the impact remains nonetheless limited. Finally, a failure to change a policy occurs if a decision is neither implemented nor does it achieve its goals and rather ends with unintended consequences. 
The concept of policy change presumes an issue and problem which is defined in the process of agenda setting. To understand change, researchers need to consider institutions distributing powers, responsibilities and capacities to act, as well as procedures regulating processes. Last but not least, policies are changed by actors (policymakers) who work on an agenda, make decisions on alternative options to achieve their aims, implement decisions and in some way or another evaluate the outcome and impact. Certainly, there can be change without policymaking, not only in society or the social field that a policy addresses, but also in the institutions enabling or constraining policymaking or in the specific actor constellation, power structure or standard operating procedures. As a rule, these conditions change continuously, they evolve over time and drift away from the status quo, and this evolution can support or obstruct policymaking and policy change. Policies can contribute to evolution if they achieve incremental drift towards an envisaged aim in a series of marginal revisions of the status quo. Change can also occur in a discontinuous oscillation of evolution and decisive shifts in a certain direction, in a temporal pattern that proponents of historical institutionalism conceptualized as path-dependence and critical junctures, and that in policy science is described as punctuated equilibrium (Baumgartner and Jones 1993; Pierson 2004); that is a rather stable constellation which is interrupted by significant change triggered by 'focusing events' (Birkland 1998) or 'windows of opportunity' (Kingdon 2003: 184-90).

The basic concept of policy change simply describes a deviation from the status quo. The categories suggested to distinguish types of change are descriptive, they do not tell us anything about the evaluation of change nor its consequences. By contrast, the concept of policy innovation has normative connotations. Innovation is preferred to the status quo, and it is achieved by policymakers working on an agenda, although not necessarily by individuals or groups affected by the envisaged policy change. If an issue appears on the agenda, policymaking is aiming at something new, a policy that amends existing rules, services, resource allocation etc., and amendments are defined by normative criteria. Yet the attribute 'new' describes neither an objective fact nor does it generally appear as positive. An innovative policy is 'perceived as something new by an individual or other object of adoption' (Rogers 2003: 12 ), and it is positively evaluated by those who make the policy and aim at a significant change improving the status quo.

Beyond this very generic description of innovation, we find various definitions of the concept in the scholarly literature, mainly in economics (Fagerberg 2005) but meanwhile also in policy science and public administration (Ansell 
and Torfing 2014b: 4; Jordan and Huitema 2014a; Howlett 2014; Torfing and Triantafillou 2016a: 7). The following features are particularly relevant:

- First, to qualify as innovation, policy change should lead to significant modification of programmes, laws or executive action. Compared to existing policy practices, it should 'introduce non-status quo, if not necessarily entirely novel, policy components or combinations of components which often result in new outcomes' (Howlett 2014: 396). As a rule, significant change involves a reallocation of resources, costs and benefits, or power.

- Second, a policy is innovative if it covers the agenda of policymaking and if it alters the status quo in a direction that is intended by the responsible actors. In democratic politics, these actors are accountable to the people and their intentions on policymaking should be in accordance with the will of the people.

- Third, innovation includes new ideas on how problems can be solved. It should imply substantive and relevant change, which is explicitly justified as a departure from routines and established practices. As such it should promise to solve the problems addressed or improve deficient conditions.

- Fourth, innovation leads to effective change with lasting effects (Polsby 1984: 8).

As a rule, significant policy change is associated with changes in power structures or institutions. Therefore, the concept of policy innovation should include deliberate change of formal rules of policymaking, informal standard operating procedures, patterns of interactions and power relations among actors involved in policymaking. If policy innovation is about a change of institutions, I will talk about institutional reform, provided that it ends with a significant, intended, justified and effective change. The general notion of reform is often used in the literature and in political practice to describe a policy change. However, I prefer to use the term in the specific sense of a revision of a 'form', that is a structure enshrined in institutional rules.

Regardless of whether policy innovation concerns specific policies or institutions, it does not necessarily entail a radical transformation nor rapid change. Although change should be significant, it must not alter entire structures, rules, procedures, aims, programmes and measures to be considered as innovation. Moreover, time can structure the process of innovation, but it is not a defining attribute of the concept. As any process, policy innovation evolves in time, and often in cycles of progressive and regressive developments (Breznitz and Ornston 2018). In contrast to incremental or gradual evolution, innovation brings about significant changes in a direction intended by policymakers and accepted by those affected. How long this process takes is irrelevant, as long as we can actually observe significant and effective policy change. 
The concept of policy innovation is often linked to other concepts such as invention, imitation or policy learning. Invention means a creative act leading to new ideas. It results from a cognitive process and finds expression in new knowledge, and it initiates and stimulates innovation processes (Fagerberg 2005: 5-6). Policy innovation, like policy change, is a political process aiming at turning an invention into practice. Imitation is often considered as part of policy innovation since it contributes to disseminating an invention or innovation within a political system or an organization, within the market or society. Thus, imitation and diffusion could lead to innovation at a higher level of a system, as they drive change in the intended direction in this wider context. Like invention, they may constitute a specific process in policy innovation (Jordan and Huitema 2014b: 391). However, imitation of a policy as such does not guarantee that ideas or new practices spread across jurisdictions. Moreover, conditions explaining imitation are different from those supporting innovation.

Closely related to policy innovation is the concept of policy learning (Bennett and Howlett 1992; Dunlop and Radaelli 2013). In order to find new solutions to problems, policymakers have to learn, but those who only adjust to new situations are also learning, even if they only adopt or copy a model or receive new information. Learning mainly consists of developing knowledge, either about ways to pursue given goals or about conditions which suggest a revision of goals (Argyris and Schön 1978). It has also been conceptualized as a change in ideas, beliefs, perceptions or opinions (Sabatier 1987). Hence, learning mainly affects the cognitive dimension of behaviour, whereas policy innovation requires a change in behaviour and affects patterns of interaction and power structures.

\section{PLAN OF THE BOOK}

Is policy innovation to be expected in multilevel governance? If so, under what particular conditions is it likely to occur? Which particular patterns of multilevel governance are conducive to innovation and which ones more or less obstruct change? These questions are addressed in the following chapters. In order to come to conclusions, the first part (Chapters 2, 3 and 4) summarizes and discusses the theoretical literature, which suggests different answers to these questions.

The next chapter reviews the literature on multilevel governance and policymaking in federal systems, the EU and transnational intergovernmental relations. The publications in this field reveal the varieties of multilevel governance and the diverse conditions that have to be considered. Among the different theoretical approaches, many tend to support a sceptical assessment of the innovative potential of multilevel governance, although we also find 
arguments justifying a more optimistic view. Some theories explain dynamics and change in complex multilevel settings but focus on endogenous change of power structures and actor constellation rather than on intended innovation of policies. Other approaches on multilevel policymaking explain why incremental change can be expected at best. While we can take it for granted that policy innovation is the exception rather than the rule in multilevel governance, there are no reasons to rule out significant, effective and intended change. Therefore, we need to understand the particular social mechanisms, that is, processes which turn causes into effects, and conditions making innovation feasible or fostering innovation.

To identify mechanisms of change, Chapter 3 introduces theories of policy change and institutional change. Institutions enable policymaking by establishing enduring responsibilities, rules, norms and procedures. They stabilize interactions and enable coordinated action, but they constrain change even when ineffective institutions have to be amended. Therefore, institutionalist approaches usually explain gradual change whereas significant change is regarded as an exceptional event occurring coincidentally. Actor-centred accounts suggest different patterns of change depending on particular mechanisms. Policy theories focus on processes of change, be it collective learning, the conversion of belief systems or paradigms, shifts in power relations or a reallocation of resources. As policy change and innovation concern both the substance of a policy and the institutional context, both strands of theoretical reasoning are relevant and warrant attention.

Chapter 4 links these theories with research to multilevel governance. First it emphasizes the dynamic interplay of institutions and non-institutionalized processes in order to appropriately include theories of institutional change. Therefore, instead of institutions, the focus is on arenas; that is, actual venues of policymaking within the context of institutions. Although institutional constraints should not be neglected, it is shifts of policies and powers from one arena to another that provides potential for policy change. Whether change leads to innovation depends on additional driving forces and conditions, which will also be discussed in Chapter 4 . It will conclude with an analytical framework and assumptions summarizing the theoretical reasoning.

Chapter 5 and 6 summarize findings from case studies on energy and climate policy in transnational, national and local contexts and on fiscal equalization in federal states. The cases exemplify more or less successful instances of policy changes in different multilevel systems. They reveal varying institutional settings, governance mechanisms such as regulation, negotiation, cooperation or mutual adjustment, and additional conditions that can be identified as conducive for policy innovation. Moreover, they point out the interplay of policy change and institutional change. By illustrating mechanisms of policy change and innovation in multilevel governance, and by highlighting the particular 
conditions enabling or constraining these mechanisms, the studies should endorse the assumptions derived from the theoretical approach and demonstrate that significant change and successful innovation can occur in multilevel governance. However, they are not meant to test hypotheses.

Based on theoretical reasoning and the illustrative case studies, Chapter 7 systematically discusses enabling and constraining conditions of multilevel governance and processes which contribute to policy innovation. It briefly summarizes basic societal developments which explain the rise of multilevel governance and the intensifying conflicts complicating policymaking. As to structures, linkages between multiple arenas (like intergovernmental relations, executive-legislative relations, party competition, inter-administrative relations, expert panels) are emphasized. As suggested by the case studies, flexibility of the institutional framework linking multilevel and intragovernmental politics is essential, as are appropriate arrangements of processes in different arenas in order to induce innovations, manage conflicts and evade constraints.

The concluding chapter summarizes the gist of the argument and addresses implications for research and practice. One general conclusion relates to the complexity of multilevel governance and its ambivalent impact on policymaking. In general, the inclusion of many actors and volatile patterns of interactions can be a reason for governance failure. On the other hand, diversity of perceptions and ideas can contrast the confrontation of different interests, while shifting actor constellations and the pressure to avoid policy deadlock can induce creative solutions. Thus, complexity of governance should be regarded not only as a necessary evil but also as a precondition to solve complex policy problems in a democratic way. 